\title{
An empirical investigation for measuring the performance of supply chain operation: A case study of healthcare industry
}

\author{
Saeede Nateghinia*, Somayyeh Abdolhosseini and Shahin Habibi
}

${ }^{a}$ Department of Industrial Management, Central Tehran Branch, Islamic Azad University, Tehran, Iran

\begin{tabular}{l}
\hline C H R O N I C L E \\
\hline Article history: \\
Received January 12, 2013 \\
Received in revised format \\
30 May 2013 \\
Accepted 5 June 2013 \\
Available online \\
June 9 2013 \\
\hline Keywords: \\
Supply chain management \\
Drug industry \\
AHP \\
SCOR
\end{tabular}

\begin{abstract}
A B S T R A C T
A supply chain is a network of facilities for procuring raw materials, transforming them into intermediate goods and then final products, and delivering them to customers through a distribution system. This paper presents an empirical investigation to measure the performance of a hospital based on the implementation of supply chain operations reference (SCOR) method. The proposed model of this paper considers five criteria including reliability, responsiveness, agility, costs and assets in one of Iranian hospitals and computes the performance of four important departments including dentistry, radiology, pharmacy and laboratory. The proposed model of this paper uses analytical hierarchy process to assign weights for all criteria to measure the overall performance. The result of this survey indicates that reliability is the most important factor in measuring the performance of medical centers.
\end{abstract}

\section{Introduction}

A supply chain is a network of facilities for procuring raw materials, transforming them into intermediate goods and then final products, and delivering them to customers through a distribution system (Holmberg, 2000; Huan et al., 2004; Johnson \& Mena, 2008). To reach integrated supply chain management, there have been tremendous efforts on developing models to investigate the elements and activities of a supply chain. The supply chain council (SCC) (Supply-Chain Council, 2006), supported by over 650 members from both academia and industry worldwide, has developed the supply chain operations reference (SCOR) model. The SCOR model is a kind of process reference technique, which is considered as an industrial standard enabling next-generation supply chain management. 
SCOR maintains a standard description of management processes, a model of relationships among the standard processes, standard metrics to compute process performance, management practices, which produce best-in-class performance, and a standard alignment to software features and functionality. Huang et al. (2005) summarized the SCOR model, its advantage along with illustrative case stories and described a computer-assisted tool to configure supply chain threaded diagram per SCOR specification.

According to Hwang et al. (2008), the SCOR model, proposed by the SCC is a standard for performance evaluation model and it has been widely embraced by many modern firms. The SCOR model capable enterprises to analyze their supply chain performance in a systematic framewok, to enhance communication among the members in the supply chain, and to design a more efficient supply chain network. To further improve the performance of the sourcing process, which is critical for various industries, Hwang et al. (2008) investigated the sourcing processes and their accompanied performance metrics in the SCOR model version 7.0. They used a questionnaire survey to collect empirical information and based on an implementation of the regression model they examined the sourcing process of SCOR at level 2 and its performance metrics. The results obtained were further extended for investigation on the sourcing process of level 3. Besides, they elaborated the institutionalization of the SCOR model and justified the project planning system based on the SCOR model. They explained that the proposed approach was feasible and valuable to supply chain managers in decision-making on various industries.

Stewart (1997) the SCOR is the first cross-industry framework for evaluating and improving enterprise-wide supply-chain performance and management. The emerging process reference framework concept is the logical extension of business process re-engineering and other process improvement efforts. SCOR structured in 4 levels and it is based on a plan, source, make, deliver framework. Lockamy III and McCormack (2004) performed an empirical investigation for linking SCOR planning practices to supply chain performance.

\section{The proposed model}

The proposed model of this paper considers the effects of four independent variables including reliability, responsiveness, agility, cost and asset management on performance of supply chain. Fig. 1 demonstrates details of our proposed study,

\section{Reliability}

Responsiveness

$$
\text { Agility }
$$

Performance of supply chain management

\section{Cost}

Asset management

Fig. 1. The proposed framework

In addition to this conceptual model, we use dimensional analysis model and plan to implement analytical hierarchy process to prioritize different items in an empirical case study of Iranian hospital during the year of 2012. Let $x_{i}$ and $y_{i}$ be the relative scores of $x^{\text {th }}$ and $y^{\text {th }}$ alternatives in terms of $i^{\text {th }}$ 
criterion, respectively. Let $w_{i}$ be the relative weight of criterion $i$ with $W=\sum_{i=1}^{n}|w i|$. Dimensional analysis (DA) for $j^{\text {th }}$ alternative is calculated as follows,

$$
D A_{j}=\sqrt[w]{\prod_{i=1}^{n}\left(\frac{x_{i}}{y_{i}}\right)^{w_{i}}}
$$

In Eq. (1), as DA is getting close to one, this means that two alternative $x$ and $y$ are near each other. Note that in Eq. (1) we use positive numbers for criteria and negative numbers for disadvantage criteria. For instance, consider the following criteria shown in Table 1.

\section{Table 1}

Attributes and necessary data

\begin{tabular}{lccc}
\hline Attribute & $x$ & $y$ & Weight (w) \\
\hline Delay & 30 minutes & 20 & 1 \\
Profit & 20 million & 25 & 1 \\
Efficiency & $30 \%$ & 95 & 1 \\
\hline
\end{tabular}

Applying Eq. (1) to numbers given in Table 1 yields the following,

$$
D A_{j}=\sqrt[3]{\left(\frac{30}{20}\right)^{-1}\left(\frac{20}{25}\right)^{1}\left(\frac{80}{95}\right)^{1}}=0.7658 .
$$

This means there is approximately a gap of $23.42 \%$ from ideal performance.

\section{The case study}

The proposed study of this paper has been implemented in one of Iranian hospitals. There are four departments, which are considered as essential for SCOR including dentistry, pharmacy, radiology and laboratory. These departments are investigated based on five criteria including reliability, responsiveness, agility, costs and assets. We use geometric mean for calculating the average numbers assigned for each criterion. Table 2 demonstrates details of our findings.

Table 2

The summary of SCOR implementation

\begin{tabular}{lccccc}
\hline & & & Criteria & \\
& Reliability & Responsiveness & Agility & Cost & Assets \\
\hline Dentistry & 0.998 & 1.29 & 0.994 & 1.2 & 0.70 \\
Pharmacy & 0.905 & 0.467 & 0.6557 & 0.69 & 0.62 \\
Radiology & 0.997 & 0.51 & 0.57 & 0.80 & 0.63 \\
Laboratory & 0.945 & 0.574 & 0.83 & 0.95 & 0.47 \\
\hline Mean & 0.960 & 0.64 & 0.73 & 0.89 & 0.65 \\
\hline
\end{tabular}

Now, we need to find the relative weights for all five criteria and the most popular technique to use analytical hierarchy process (AHP) originally developed by Saaty (1996). AHP uses a pairwise comparison between each pairs of criteria to find the relative importance of each criterion versus another one and using a simple row-column mean calculation finds the relative importance of all criteria. In our survey, the relative weights for reliability, responsiveness, agility, costs and assets have been calculated as $0.576,0.193,0.103,0.096$ and 0.031 , respectively. The consistency ratio has been calculated as 0.09 , which is well less than the minimum acceptable limit of 0.1 . Therefore, we can rely on the numbers and the final SCOR value is equal to 0.84 . 


\section{Conclusion}

In this paper, we have presented an empirical investigation to measure the performance of a hospital based on the implementation of supply chain operations reference (SCOR) method. The proposed model of this paper has considered five criteria including reliability, responsiveness, agility, costs and assets and computed the performance of four important departments including dentistry, radiology, pharmacy and laboratory. The proposed model of this paper has also implemented AHP method to assign weights for all criteria to measure the overall performance.

\section{Acknowledgment}

The authors would like to thank anonymous referees for constructive comments on this paper, which have contributed the paper.

\section{References}

Holmberg, S. (2000). A systems perspective on supply chain measurements. International Journal of Physical Distribution \& Logistics Management, 30(10), 847-868.

Huang, S. H., Sheoran, S. K., \& Keskar, H. (2005). Computer-assisted supply chain configuration based on supply chain operations reference (SCOR) model. Computers \& Industrial Engineering, 48(2), 377-394.

Huan, S. H., Sheoran, S. K., \& Wang, G. (2004). A review and analysis of supply chain operations reference (SCOR) model. Supply Chain Management: An International Journal, 9(1), 23-29.

Hwang, Y. D., Lin, Y. C., \& Lyu Jr, J. (2008). The performance evaluation of SCOR sourcing process - The case study of Taiwan's TFT-LCD industry. International Journal of Production Economics, 115(2), 411-423.

Johnson, M., \& Mena, C. (2008). Supply chain management for servitised products: a multi-industry case study. International Journal of Production Economics, 114(1), 27-39.

Lockamy III, A., \& McCormack, K. (2004). Linking SCOR planning practices to supply chain performance: An exploratory study. International Journal of Operations \& Production Management, 24(12), 1192-1218.

Saaty,T. L. (1996). The analytic hierarchy process. RWS.

Stewart, G. (1997). Supply-chain operations reference model (SCOR): the first cross-industry framework for integrated supply-chain management. Logistics information management, 10(2), 62-67.

Supply-Chain Council(scc) (2006). Supply-chain operations reference model version 7.0 overview, < http://supply-chain.org> 